changes in either blood cells or vessel walls which would lead to diapedesis into the sinuses.

Conclusions. Both histological and experimental evidence is strongly indicative of the existence of the hæmolymph node as an organ sui generis. In the light of our present knowledge the chief practical point, however, is to recognize the capability for phagocytic destruction of red blood cells which is possessed to a high degree by certain lymphoid structures, rather than to dwell upon the individuality of the hamolymph node. The occurrence of transition forms from the node containing blood sinuses only to that with sinuses containing lymph alone renders a strict classification impossible. For practical purposes Warthin's grouping of all varieties under the heading of hamolymph nodes appears eminently satisfactory.

'To Dr. George C. Freeborn I am indebted for many valuable suggestions in connection with this investigation; to Dr. A. J. Lartigau for aid in the operative work, and to Dr. Edward Leaming for the accompanying photomicrograph.

\title{
BIBIJIOGRAPHY.
}

Lewis. Journal of Physiology, 1902, vol. xxviii., Nos. 1 and 2.

Morandi and Sisto. Archlv. per ie Sci. Med., 1901, vol, xx7., No. 13.

Retterer. Comptes Rendus de la Soc. de Biol., 1902, T. lív., p. 33.

Saltykow. Zeit. fur Heilkunde. Abtheil fur Path. Anat., 1900, S. 301.

Warthin. Journal of the Boston Society of the Medical Sciences, vol. v. p. 415 ,

Warthin. Journal of Medical Research, 1902, voi. il. p. 435.

Warthin. The american Journal of the Medical Sclences, October, 1902.

Warthin. Transactions of the Chicago Pathological Society, November, 1902, vol. v., No. 8.

Weidenreich. Anatom. Anzeiger, 1902, Ergänzungsheft, Bd. xxi., S. 47.

\section{SYPHILITIC AFFECTIONS OF THE SKIN AND OSSEOUS SYSTEM IN THE. NEWBORN.}

\author{
By W. Reynoldos Wilson, M.D., \\ OF PHILADELPHA.
}

SyPHILITIC infection may be transmitted in varying degrees of intensity. Its manifestations follow certain definite rules. Every newborn infant, the victim of transmitted syphilis, may not necessarily exhibit the taint; on the other hand, in the largest number of conceptions occurring in the earlier stages of syphilis transmissible from one or both parents, abortion or premature expulsion of the fetus is liable to result.

The opportunity of infection occurs:

1. In the presence of a coexistent infection in both parents. 'This usually results in abortion (Baginsky), although Neumann has recorded the birth of healthy infants under such conditions. 
2. In the presence of infection of the male parent alone at the time of conception. In this case the infection is transmitted directly to the fetus, and is in reality the result of direct contagion. Although the pregnancy may not be interrupted, the infant mortality is great, the children succumbing in proportion to the primariness of the infection in the parent.

3. In the presence, at the time of conception, of maternal infection alone. As in the case of paternal infection, the infant may escape transmission if the paternal disease has reached its tertiary form.

4. In the presence of maternal infection during gestation. The intensity of the infection in such instances depends upon the degree of postponement of the postconceptional infection in the mother.

According to Fournier, syphilis in the newborn may present direct congenital manifestations or indirect evidences of infection. In the latter case it is spoken of as hereditary syphilis. The lesions in hereditary syphilis may be either precocious or deferred as to the date of their appearance.

Congenital syphilis in the newborn is narked by signs of an infection the evolution of which has been completed in utero. Should the infant be born alive, it presents localized areas of separation of the epidermis in the form of blebs, accompanied by excoriation. The skin resembles the condition of maceration in stillborn infants. There is also present retrograde bony development (impcrfectly expanded thorax, craniotabes, etc.), enlargement of the liver and spleen. Such infants are usually premature.

Hereditary syphilis in its precocious form affects especially the newborn infant. It is marked by snuffes, hoarse cry, pendulous abdomen, splenic and hepatic enlargement, and the characteristic syphilides.

The subject of hereditary syphilis with deferred manifestations may present at the time of birth a perfectly healthy appearance. More frequently, however, the infants are emaciated, the skin being of a dull yellowish color and the face presenting a characteristic senile expression.

Syphilis in the newborn may be considered in reference to the skin localization as follows:

1. The pathognomonic form of eruption in early syphilis is that of a pemphigus (Gastou). The lesion may either exist as a congenital manifestation or may make its appearance at the end of the first week of life. The character of the eruption is twofold. It may appear, first, in the form of violet or reddish patches protruding slightly beyond the surface of the skin and surrounded by a zone of moderate hyperæmia. The elevation of the surface affected is due to the displacement of the epidermis by the accumulation of a sanguinolent fluid, which may rapidly change in color to a greenishyellow. The size of a fully-formed vesicle usually equals that of a small pea. The diameter, however, may reach $1 \mathrm{~cm}$. or more in 
extent. 'The border may be circular or polygonal. Rupture of the bleb leaves an ulcerated, uneven base. Recovery takes place by the formation of a brownish crust, the neighboring skin remaining reddened and squamous. Secondly, the syphiloderm may begin as a pustular eruption the lesions of which proceed rapidly to maturation and take on a varioloform appearance. If the pustules coalesce, the resulting exfoliation may assume the character of a squamous dermatitis, producing a condition resembling ichthyosis. Syphilitic pemphigus usually attacks the palmar and plantar surfaces, especially in its vesicular form. The pustular form is found most frequently in the region of the buttocks and genitalia. It may, however, show no elective tendency as to location, appearing on any part of the body or face.

Jacquet regards the pemphigus of hereditary syphilis in the newborn in the light of a developed form of a papulomacular syphilide, corresponding to that observed usually as a later manifestation. The exuberance of the lesions resulting in the bleb-like development, according to his view, is due to the normal congestion of the skin and the delicacy of the epithelial layer in the newborn.

2. A further manifestation often met with is the papuloerosive syphiloderm, which makes its appearance in the crevices of the skin, where moisture is apt to be present, as, for instance, in the genitocrural folds, the axilla, the region of the umbilicus, and the interdigital spaces. The efflorescence occurs in the form of small papules of a yellowish-gray color and a diphtheritic surface, accompanied by a local erythema. This usually results in erosion, which attacks the summit of the papules and permits the escape of a thinnish exudation. The erosion extends peripherally rather than in depth.

3. Probably the most frequently observed syphiloderm in hereditary syphilis is tluat of erytlema. The rash begins very much as a simple erythema, attacking the region of the genitalia and nates. It, however, may not be confined to these points of election, as it frequently makes its appearance on the face, especially on the forehead and body. The eruption may even extend to the scalp. 'The eruption is apt to spread rapidly, showing a tendency to infiltration, and resulting in the development of small papules, which show, as the result of erosion, a moistened surface. 'The efflorescence remaining after the disappearance of the acute erythema presents a coppercolored, papular syphilide characteristic of secondary manifestations. Frequently the papules are disposed at the verge of the anus and the commissure of the lips (Van Harlingen). There may be active desquamation resulting in the formation of thick, yellowish crusts, which, in separating, leave a moist, infiltrated base. Syphilitic erythema, when attacking the region of the umbilicus, very often results in an impetiginous rash, which terminates in local desquamation. Complicating the erythema, there is frequently observed a macular and squamous eruption of the palmar and plantar surfaces. 
4. Furunculoid lesions attacking the corium, as well as tuberculous eruptions, are not uncommonly found coincidently with the more typical skin manifestations. Gaston calls attention to the existence of a gummatous condition, which exists in the form of deep tumefactions, in the region surrounding the articulations. 'This condition must not be mistaken for the infiltration due to periarthritic abscess. It is not uncommonly seen in instances of fatal congenital syphilis.

As in acquired syphilis, the lesions are apt to be symmetrical and are characterized by polymorphism. Owing to the latter characteristic, it is sometimes difficult to differentiate the varieties in syphilitic erythema, the simple form frequently merging into the squamous and impetiginous forms.

Paronychia may bc mentioned among the syphilides appearing in the newborn. Although the infiltration surrounding the matrix may be extensive, it is not likely to result in ulceration. Fissures occurring at the borders of the mucous membrane are conmonly seen, situated in the region of the anus and lips. Fissures in the epidermis of the scrotum, and, in the female, in the region of the fourchette, may be observed.

Mucous Membranes. Syphilis of the mucosæ may appear frequently as the primary manifestation in hereditary transmission. In this way the coryza may appear as the initial manifestation. The nasal secretion is at first sanious, becoming afterward greenish and purulent. It is frequently mixed with blood. It is irritating to the adjacent skin and often fetid. The crusts which form from the drying secretions may give rise, through their detachment, to epistaxis. The mucous membrane becomes swollen and the submucosa infiltrated, often to such extent as to interfere with the nasal respiration. The buccal mucous membrane, the tongue, the hard palate may become individually the seat of mucous patches, the sites of which offer local areas of ulceration in the process of cicatrization. The pharynx is usually swollen and reddened. The laryngeal mucous membrane may also partake of the hyperamia and swelling, causing characteristic hoarseness, and leading often to extinction of the voice. Dyspnœa may sometimes occur, simulating laryngismus stridulus and resulting rapidly in dcath by asphyxia. Inflammation of the middle ear, accompanied by otorrhoea, is of inf requent occurrence.

The Osseous System. The changes in the osseous system affect the long bones as a rule, less frequently the phalanges. The pathological changes in the cranial bones are usually associated with the evolution of infantile syphilis in its later stages. The bones of the head may present, however, a condition of craniotabes. Undue protrusion of the parietal eminences with deeply-marked sutures (natiform cranium) may rarely be observed. Microcephalus or hydrocephalus may be present in cachectic infants.

The abnormalities occurring in the long bones affect usually the juncture of the diaphysis and epiphysis. In an undeveloped state 
the lesion may exist as an osteochondritis, which may offer no external evidence. In acute or progressive form it is marked clinically by an indifferent swelling, which may not be detected beneath the soft tissue; occasionally by a palpable enlargement. The condition may make its appearance soon after birth. If the lesions be multiple and pronounced in development they may present the appearance of pseudosyphilitic infantile paralysis. The clinical picture of this disease is described by Parrot. When the infant in a pronounced case is suspended by the axillæ the extremities hang flaccid. If the skin is pinched the muscles move, but the position of the member is not changed. On the other hand, the infant will suffer without resistance such displacement of its extremities. If the legs are extended while the child is in the dorsal decubitus they will resume their flexed position, but the movement is accompanied by pain. The joints may be tumefied. Crepitation and fluctuation may be present. Such extensive involvement usually results in a fatal outcome. 'The inflammation and loss of continuity producing the symptoms just described are due, according to Gastou, to a justo-epiphyseal osteitis. 'The suppuration which is present usually invades the joint and leads uniformly to the destruction of the cartilage and the separation of the epiphysis. The apparent muscular relaxation present in such cases may be confused with paralysis of central origin, due to such causes as intracranial hemorrhage and obstetrical traumatism. It may likewise simulate the muscular immotility present in fractures and luxations. The condition is not to be confused with epiphyseal separation due to the destruction of the cartilage, found in the putrefactive invasion of the tissues in macerated infants. In instances of the purulent destruction of the epiphyseal attachment, the presence of streptococcus denotes the possibility of the septic process occurring secondarily to the specific inflammation. The lesion may be found at either end of the femur, at the distal end of the tibia, and the bones of the forearm (Ziegler).

As to the pathology, the site of the lesion is the so-called zone of proliferation-i.e., the transitional cartilaginous area that separates the epiphysis from the shaft of the bone. According to Kassowitz and Heubner, the progress of the condition may be divided into three stages: 1. A premature deposit of the primary calcareous infiltration in the original cartilaginous substance. 2. An irregular invasion by this calcifying process of the area of intermediary cartilage (the area in which the cartilage cells begin to arrange themselves to form the primary cartilaginous trabeculæ), with an overgrowth of the cartilaginous trabeculæ and with the premature deposit of bone. 3 . The development of a granulation zone between the epiphysis and apophysis, followed in some instances with the actual secretion of pus.

Macroscopically the yellowish line of demarcation at the apophysoepiphyseal juncture corresponding to the zone of proliferation, found 
post-mortem in newborn infants, represents the early stage of the process just described.

The digital phalanges may be the seat of the bony involvement in congenital and hereditary syphilis. The periosteum and fibrous structure surrounding the bone are usually affected. Secondarily, the skin and subintegumentary tissues become involved. Suppurative changes resulting in ulcerations are usually not to be observed, on account of the readiness with which the specific infiltration yields to treatment. 'The proximal phalanx is more frequently involved than the distal phalanx. The finger is apt to be swollen at its base, presenting a pyriform appearance with the characteristic discoloration of the skin. Baginsky has observed a bony deformation of the fingers, resulting in syndactylism in a syphilitic child.

\section{A STUDY OF THE CALORIC NELDS OF PREMATURE INFANTS.}

By John Lovett Morse, A.M., M.D.,

INSTRUCTOR IN DISEASES OF CHILDREN, HARVARD MEDICAL gCHOOL; ASSISTANT PHYSICJAN AT THE CHILDREN'S hOSPITAL AND AT THE INFANTS' HOSPITAL, BOSTON.

Vikrords and Rubner were the first to investigate the metabolisin of the infant. Camerer, in 1889 , collected a large amount of material and endeavored to determine in heat units the nutritive needs of infants of various ages. He calculated the caloric contents of breast milk on the basis of Pfeiffer's analyses. A considerable number of observations have been made by different men since that time. Fach one has, as a rule, made but one or two. Most of them have been made on breast-fed infants; a few on artificially fed. Some of them have extended over the first year, but most of them only over short periods of time. Czerny and Keller, in their hand-book published in 1902, have reviewed the work of previous observers in detail and added a considerable amount of material of their own. Since then Beuthner has studied three cases, one of which was fed entirely on breast milk, the others partly on breast milk and partly on artificial food. In 1902 he summed up the cases fed on breast milk hitherto studied in private practice. $\mathrm{He}$ included the cases of Ahlfeldt (2), Camerer (4), Feer (3), Hähner (4), Laure (1), Pfeiffer (2), Weigelin (1), Oppenheimer (1), and his own (3). The average number of calories per kilo taken daily was as follows:
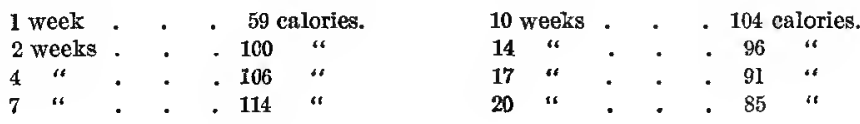